(2) Open Access Full Text Article

\title{
Importance of organizational culture: a model for increased engagement
}

This article was published in the following Dove Press journal:

Journal of Multidisciplinary Healthcare

30 September 2016

Number of times this article has been viewed

\section{Meelad Sayma \\ Tomos Luke Treharne \\ Hywel Rhys Williams \\ Peninsula College of Medicine and Dentistry, Plymouth, UK}

Correspondence: Meelad Sayma

Knowledge Spa, Royal Cornwall Hospital

Trust, Treliske, Truro, Cornwall TR I

3HD, UK

Email meeladsayma@yahoo.co.uk

\section{Dear editor}

We read with great interest the article by Nilsen et al, ${ }^{1}$ discussing how nursing leaders perceive their interactions and support levels from both peers and those in more senior leadership positions - in this case the municipal health director. Of particular interest was the conclusion of the paper, calling for greater coherence between different levels of leadership in the Norwegian health care setting.

The paper highlights a key difficulty in ensuring a cohesive leadership unit, to effectively manage increasingly scarce health care resources. The "disconnect" between leadership levels is not an uncommon situation in health care settings. ${ }^{2}$ One particularly interesting method to overcome this disconnect has been highlighted in the health care management literature in the use of written commitments or "compacts". 3,4

These compacts have been used in the Virginia Mason Medical Centre achieving increased engagement from clinical staff following a call from the upper-level management to turn around this struggling hospital. Leaders insisted on a "written physician compact" and separate "management compact" ensuring that both leaders and lower-level staff had an understanding of what was required of them and a psychological stake in organizational success, thus increasing engagement between all levels of staff. The success of these compacts, coupled with the introduction of the Toyota production system, resulted in better staff satisfaction and also in large financial savings for the organization. ${ }^{5,6}$

The use of compacts - written and signed statements declaring what is expected of a certain group of employees - is a cheap and potentially effective way of ensuring that each group of staff knows what is expected of them, and when used correctly has the potential to bridge the disconnect between different levels of leaders. ${ }^{3}$

\section{Disclosure}

The authors report no conflicts of interest in this communication.

\section{References}

1. Nilsen ER, Olafsen AH, Steinsvåg AG, Halvari H, Grov EK. Stuck between a rock and a hard place: the work situation for nurses as leaders in municipal health care. J Multidiscip Healthc. 2016;9:153-161. 
2. Gauld R, Horsburgh S. Healthcare professionals' perceptions of clinical governance implementation: a qualitative New Zealand study of 3205 open-ended survey comments. BMJ Open. 2015;5(1):e006157.

3. Orlikoff JE, Kaplan GS. Put it in writing. Trustee. 2012;65(8):33-36, 2.

4. Heifetz R, Grashow A, Linsky M. Leadership in a (permanent) crisis. Harv Bus Rev. 2009;87(7-8):62-69, 153.
5. Blackmore CC, Edwards JW, Searles C, Wechter D, Mecklenburg R, Kaplan GS. Nurse practitioner-staffed clinic at Virginia Mason improves care and lowers costs for women with benign breast conditions. Health Aff (Millwood). 2013;32(1):20-26.

6. Bohmer RM, Ferlins EM. Virginia Mason Medical Center. Boston, MA: Harvard Business School; 2006. 


\section{Authors' response}

Etty R Nilsen'

Anja H Olafsen'

Anne Grethe Steinsvåg ${ }^{2}$

Hallgeir Halvari'

Ellen K Grov ${ }^{3}$

'Department of Strategy and Finance, School of Business, University College of Southeast-Norway, ${ }^{2}$ Department of Nursing Science, Faculty of Health Sciences, University College of Southeast-Norway, Kongsberg, ${ }^{3}$ Department of Nursing and Health Promotion, Faculty of Health Sciences, Oslo and Akershus University College, Oslo, Norway

Correspondence: Etty R Nilsen

School of Business, University College of Southeast-Norway, PO Box

235, N-3603 Kongsberg, Norway

Tel +4797021325

Fax +4732 II 7 I I 0

Email etty.nilsen@hbv.no

\section{Dear editor,}

Thank you very much for your very interesting and highly relevant comment on our article. ${ }^{1}$ We acknowledge the organizational challenge in the health care field, especially in the municipal health care service, where 1) the geographical distance between peers and between the management levels in itself forms a barrier, and 2) there is a lack of regular and natural meeting places for both planned and ad hoc contact.

We welcome suggestions for interventions to ease the communication and cooperation between the management levels and, at the same time, we anticipate that multiple interventions of both structural and cultural nature will be necessary. Your suggested intervention will, in our opinion, raise consciousness with regard to the importance of mutual information and increase the level of engagement and possibly the support from senior management. However, it represents a focus on the information and reflections that can be codified. As such, it only partly solves the problem since it omits focus on unplanned exchange and on the sharing of tacit knowledge.

Furthermore, our empirical material is drawn from a municipality, whereas your example is from a hospital. As such, these two contexts are quite different, and we assert that it complicates the issue even more in a municipality, which is an umbrella organization, made up of several geographically dispersed organizations.

More research is needed, and we anticipate that the same challenges apply to other contexts such as schools, and that the health care field may learn from research in these other fields.

\section{Disclosure}

The authors report no conflicts of interest in this communicaton.

\section{References}

1. Nilsen, EN, Olafsen, AH, Steinsvåg AG, Halvari, H, Grov EK. Stuck between a rock and a hard place: the work situation for nurses as leaders in municipal health care. J Multidiscip Healthc. 2016;9:153-161.

Dove Medical Press encourages responsible, free and frank academic debate. The content of the Journal of Multidisciplinary Healthcare 'letters to the editor' section does not necessarily represent the views of Dove Medical Press, its officers, agents, employees, related entities or the Journal of Multidisciplinary Healthcare editors. While all reasonable steps have been taken to confirm the content of each letter, Dove Medical Press accepts no liability in respect of the content of any letter, nor is it responsible for the content and accuracy of any letter to the editor.

\section{Publish your work in this journal}

The Journal of Multidisciplinary Healthcare is an international, peerreviewed open-access journal that aims to represent and publish research in healthcare areas delivered by practitioners of different disciplines. This includes studies and reviews conducted by multidisciplinary teams as well as research which evaluates the results or conduct of such teams or health care processes in general. The journal covers a very wide range of areas and welcomes submissions from practitioners at all levels, from all over the world. The manuscript management system is completely online and includes a very quick and fair peer-review system. Visit http://www.dovepress.com/ testimonials.php to read real quotes from published authors. 